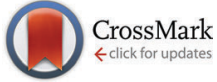

Cite this: J. Mater. Chem. B, 2015, 3, 4993

Received 12th March 2015, Accepted 14th April 2015

DOI: $10.1039 / c 5 t b 00458 f$

www.rsc.org/MaterialsB

\section{Photostable AIE fluorogens for accurate and sensitive detection of S-phase DNA synthesis and cell proliferation $\dagger$}

\author{
Yueyue Zhao, ${ }^{\text {ab }}$ Chris Y. Y. Yu, ${ }^{\text {ab }}$ Ryan T. K. Kwok, ${ }^{\text {ab }}$ Yilong Chen, ${ }^{\text {ab }}$ Sijie Chen, ${ }^{\text {ab }}$ \\ Jacky W. Y. Lam ${ }^{\mathrm{ab}}$ and Ben Zhong Tang*abc
}

Two azide-functionalized tetraphenylethene derivatives with AIE features are synthesized and used as fluorescent agents for detecting S-phase DNA synthesis and cell proliferation based on EdU assay. Compared to the Alexa-azide dye, a commercial DNA bioprobe, the AIE fluorogens show better photostability and sensitivity, making them promising alternatives.

DNA is a biomacromolecule and carries genetic instructions. It is important in the development and function of living organisms. The S-phase is one of the processes in the cell cycle, where DNA synthesis or replication occurs. Due to its biological importance, scientists have put great efforts to develop techniques for better understanding of the molecular mechanisms for DNA synthesis, especially, in complicated bio-systems. ${ }^{1,2}$ The enthusiasm has led to the development of many small molecular reporters that can bind to DNAs via intercalative, electrostatic and groove binding interactions. ${ }^{3}$

Radioactive probes are the primitive methods for the selective labelling of mitotically active cells but suffer from several disadvantages. First, the radioactive reagents are hazardous, and their high cost and time-consuming procedures have limited their use for rapid high-throughput studies. ${ }^{4}$ The microscopic images of the labelled DNAs show poor resolution and a low signal-to-noise ratio. Moreover, no simultaneous characterization of the proliferating cells is permitted by these labelling techniques. On the other hand,

\footnotetext{
${ }^{a}$ Department of Chemistry, Institute for Advanced Study, Division of Biomedical Engineering, Division of Life Science, State Key Laboratory of Molecular Neuroscience, Institute of Molecular Functional Materials, The Hong Kong University of Science and Technology, Clear Water Bay, Kowloon, Hong Kong, China.E-mail: tangbenz@ust.hk

${ }^{b}$ Guangdong Innovative Research Team, SCUT-HKUST Joint Research Laboratory, State Key Laboratory of Luminescent Materials and Devices, South China University of Technology, Guangzhou 510640, China

${ }^{c}$ HKUST Shenzhen Research Institute, No. 9 Yuexing First RD, South Area, Hi-tech Park, Nanshan, Shenzhen 518057, China

$\dagger$ Electronic supplementary information (ESI) available: Synthetic route and characterization of $\mathrm{Cy}-\mathrm{Py}-\mathrm{N}_{3}$; PL spectra of TPE-Py- $\mathrm{N}_{3}$ and $\mathrm{Cy}-\mathrm{Py}-\mathrm{N}_{3}$; flow cytometry of TPE-Py- $\mathrm{N}_{3}$ and Cy-Py- $\mathrm{N}_{3}$; MTT assay and photostability of TPE$\mathrm{Py}-\mathrm{N}_{3}$ and $\mathrm{Cy}-\mathrm{Py}-\mathrm{N}_{3}$. See DOI: $10.1039 / \mathrm{c} 5$ tb00458f
}

the fluorescence labelling has been used broadly as a 'gold standard' method in cell biology because it offers rapid detection, high sensitivity and less cytotoxicity. For example, incorporation of 5-bromo-2-deoxyuridine (BrdU), a thymidine analogue, into newly synthesized DNA has demonstrated many advantages than those techniques employing radioactive nucleosides. ${ }^{5-8}$ Nevertheless, the BrdU assay also has some limitations such as denaturation of DNA to allow targeting by antibodies, harsh treatment conditions (heat, acid and nuclease), and limited penetration of antibodies through the fixed tissue.

More recently, a direct S-phase measurement using 5-ethynyl2'-deoxyuridine (EdU), another thymidine analogue, has been introduced. $^{9-11}$ In this method, the EdU with terminal alkyne functionality was first incorporated into newly synthesized DNA. The click reaction of the alkyne unit with a fluorescent dye with an azide group is then catalysed by the $\mathrm{Cu}(\mathrm{I})$ complex, generating dye-labelled double-stranded DNA.

Conventional organic fluorogens have been used in EdU assay. These fluorogens show strong light emission in solution but emit weak or no luminescence when aggregated due to the formation of detrimental species such as excimers, which decay through non-radiative pathways. This ubiquitous phenomenon is recognized as aggregation-caused quenching (ACQ) or concentration quenching. ${ }^{12-14}$ To avoid molecular aggregation, ACQ fluorogens have to be used at low concentration, which results in low photo-bleaching resistance, weak emission and poor photosensitivity. More importantly, to achieve good water solubility and better molecular dispersion, the ACQ fluorogens applied in DNA synthesis detection have to be decorated with multiple charges and highly polar species. These charged fluorogens, however, generally have poor permeability and biocompatibility as well as technical challenge in synthesis and high cost. Thus, the development of fluorescent probes for detecting DNA synthesis with a simple synthetic route, low cost and high quantum efficiency in the aggregated state is urgently pursued.

In recent years, the study on fluorogens with aggregationinduced emission (AIE) characteristics has been a hot research topic. 


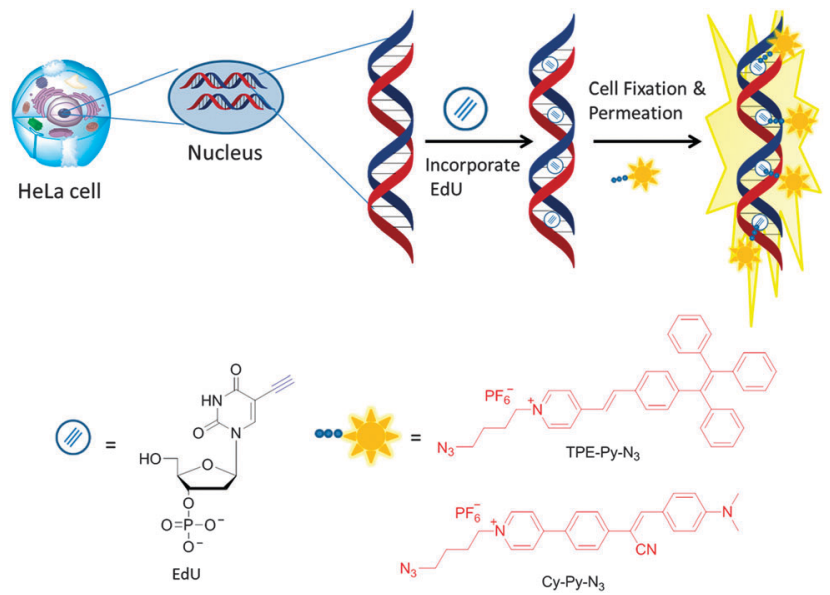

Scheme 1 DNA synthesis detection by AlEgens through EdU assay.

Unlike ACQ dyes, AIE fluorogens (AIEgens) exhibit no or weak emission in dilute solution but strong fluorescence upon aggregate formation or in the solid state.$^{15}$ Mechanistic studies reveal that restriction of intramolecular motion (RIM), including rotation and vibration, in the aggregated state is the main cause for the AIE effect. By taking such an advantage, various AIEgens have been designed and successfully applied in many biological applications such as cell labelling and turn-on detection of biomacromolecules. $^{16-20}$

Through rational molecular design, a number of AIEgens with emission colours varying from blue to red have been successfully applied in organelle imaging such as mitochondria and lysosome. ${ }^{21-23}$ However, few examples of nuclei staining and DNA synthesis detection are presented. In this work, we report the biological applications of two azide-functionalized AIEgens, abbreviated as TPE-Py- $\mathrm{N}_{3}$ and $\mathrm{Cy}-\mathrm{Py}-\mathrm{N}_{3}$, in detecting DNA synthesis and cell proliferation based on the techniques of EdU assay (Scheme 1). The results show that the present AIEgens show better performances than the Alexa-azide dye, commercial available fluorogens for detecting DNA synthesis.

TPE-Py- $\mathrm{N}_{3}$ was prepared and synthesized according to our previous publication. ${ }^{24}$ In order to generate a new AIEgen with red emission for the application in DNA synthesis detection, introduction of a D-A system into the molecular structure of AIEgen was employed. Hence, luminogen $\mathrm{Cy}-\mathrm{Py}-\mathrm{N}_{3}$ was designed, where the dimethylaminophenyl group acts as an electron-donor, while the nitrile and pyridinium units function as electron acceptors. It was prepared by following the synthetic route shown in Scheme S1 in the ESI. $\dagger$ Its molecular structure was characterized by ${ }^{1} \mathrm{H}$ NMR and mass spectroscopies with satisfactory results (Fig. $\mathrm{S} 1$ and $\mathrm{S} 2, \mathrm{ESI} \dagger$ ). The photoluminescence (PL) spectra of TPE-Py- $\mathrm{N}_{3}$ in a dimethyl sulfoxide (DMSO)-water mixture and $\mathrm{Cy}-\mathrm{Py}-\mathrm{N}_{3}$ in a DMSO-toluene mixture are shown in Fig. S3 and S4 (ESI $\dagger$ ). TPE-Py- $\mathrm{N}_{3}$ shows very weak yellow emission in dilute DMSO solution $(10 \mu \mathrm{M})$. Gradual addition of water into the DMSO solution has weakened the light emission due to the twisted intramolecular charge transfer (TICT) effect. ${ }^{25}$ At a water fraction exceeding $90 \%$, the emission strengthens again owing to the formation of the TPE-Py- $\mathrm{N}_{3}$ aggregate. On the other hand,
$\mathrm{Cy}-\mathrm{Py}-\mathrm{N}_{3}$ is weakly fluorescent in DMSO solution. In the presence of a less polar solvent of toluene, the emission of $\mathrm{Cy}-\mathrm{Py}-\mathrm{N}_{3}$ becomes stronger and shifts to the bluer region. The higher the toluene fraction, the stronger and bluer is the light emission. Upon addition of $70 \%$ toluene fraction in DMSO, the emission enhances markedly. These PL results suggest that both TPE$\mathrm{Py}-\mathrm{N}_{3}$ and $\mathrm{Cy}-\mathrm{Py}-\mathrm{N}_{3}$ are AIE-active with strong emission in the aggregated state. As biosensing is always conducted in cell culture medium, the AIE feature of TPE-Py- $\mathrm{N}_{3}$ and $\mathrm{Cy}-\mathrm{Py}-\mathrm{N}_{3}$ in PBS buffer solution is examined. The PL results reveal that TPE-Py- $\mathrm{N}_{3}$ retains its AIE property in PBS buffer (Fig. S5, ESI $\dagger$ ). However, only a weak fluorescence is detected in the PBS buffer solution of $\mathrm{Cy}-\mathrm{Py}-\mathrm{N}_{3}$, possibly due to the partial dissolution of the dye molecule. Noteworthily, its emission can be turned on when bound to biomacromolecules owing to the activation of the RIM process. The quantum yields of both AIEgens in DMSO solution are negligible. In the solid state, TPE-Py- $\mathrm{N}_{3}$ shows a quantum yield of $17.7 \%$, which is nearly 12 -fold higher than that $(1.5 \%)$ of $\mathrm{Cy}-\mathrm{Py}-\mathrm{N}_{3}$ (Table $\left.\mathrm{S} 1, \mathrm{ESI} \dagger\right)$.

The capability of the two AIEgens in the detection of DNA synthesis in proliferating HeLa cells was first studied by the method depicted in Scheme 1. When DNA synthesis commences, the cells will take up EdU in solution. The azide groups, TPE-Py- $\mathrm{N}_{3}$ and $\mathrm{Cy}-\mathrm{Py}-\mathrm{N}_{3}$, can then react with the alkyne group of EdU in the presence of the $\mathrm{Cu}(\mathrm{I})$ complex. This fluorescently labels the DNA and makes the nuclei emissive. To achieve this, HeLa cells were incubated in the modified essential medium with EdU for $6 \mathrm{~h}$. Afterwards, they were fixed and stained with AIEgens in Tris buffer containing $\mathrm{CuSO}_{4}$ and ascorbic acid for $30 \mathrm{~min}$. As shown in the fluorescence images in Fig. 1, the nuclei of HeLa cells emit intense light upon photoexcitation. In contrast, the HeLa cells without EdU labelling, which serve as controls, display no detectable fluorescence after being subjected to the same staining conditions (Fig. S6, $\mathrm{ESI} \dagger$ ). This result proves that the origin of the nuclei fluorescence comes from the DNA synthesis and EdU incorporation and is unlikely due to the direct staining of the nucleus by the AIEgens. The PL from the nuclei can be discernible even when the EdU
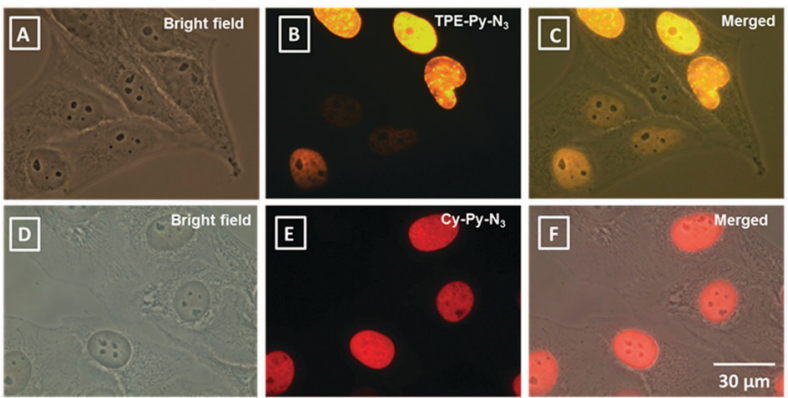

Fig. 1 Detection of S-phase DNA synthesis in HeLa cells by fluorescence microscopy. The HeLa cells were labelled with EdU by incubating in modified essential medium with EdU for $6 \mathrm{~h}$. (A and D) Bright-field, ( $B$ and $E$ ) fluorescent and ( $C$ and $F$ ) merged images of fixed HeLa cells stained with (A-C) TPE-Py- $\mathrm{N}_{3}$ and $(\mathrm{D}-\mathrm{F}) \mathrm{Cy}-\mathrm{Py}-\mathrm{N}_{3}$ in Tris buffer for $30 \mathrm{~min} .[\mathrm{EdU}]=\left[\mathrm{TPE}-\mathrm{Py}-\mathrm{N}_{3}\right]=\left[\mathrm{Cy}-\mathrm{Py}-\mathrm{N}_{3}\right]=20 \mu \mathrm{M}$; excitation wavelength: $330-385 \mathrm{~nm}\left(\mathrm{TPE}-\mathrm{Py}-\mathrm{N}_{3}\right)$ and $520-560 \mathrm{~nm}\left(\mathrm{Cy}-\mathrm{Py}-\mathrm{N}_{3}\right)$. All the images share the same scale bar $=30 \mu \mathrm{m}$. 


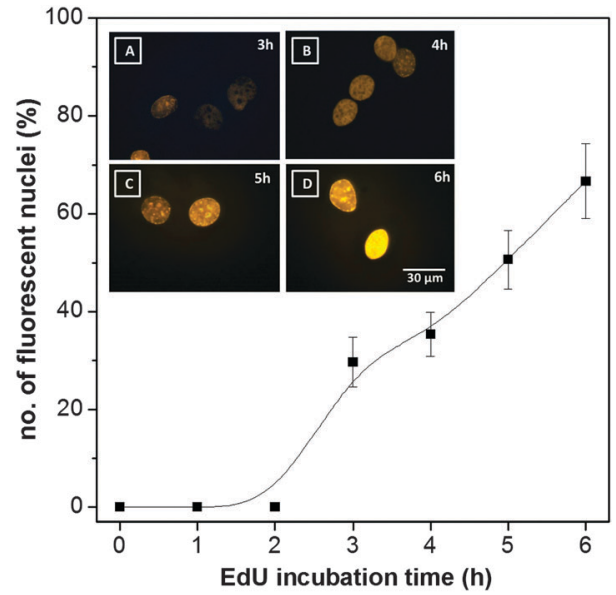

Fig. 2 Quantitative analysis of HeLa cells with increasing incubation time after EdU incorporation. Inset: fluorescence images of nuclei stained by $\mathrm{TPE}-\mathrm{Py}-\mathrm{N}_{3}$. $[\mathrm{EdU}]=\left[\mathrm{TPE}-\mathrm{Py}-\mathrm{N}_{3}\right]=20 \mu \mathrm{M}$; excitation wavelength: $330-385 \mathrm{~nm}$. All images share the same scale bar $=30 \mu \mathrm{m}$.

incubation time is short to $3 \mathrm{~h}$ (Fig. 2). Certainly, the longer the incubation time, the more emissive will be the nuclei. About $50 \%$ of cells undergo DNA synthesis after $5 \mathrm{~h}$ of EdU incorporation. The progressive PL enhancement of TPE-Py- $\mathrm{N}_{3}$ and $\mathrm{Cy}-\mathrm{Py}-\mathrm{N}_{3}$ along with EdU incubation time implies that the AIEgens are able to monitor the process of DNA synthesis as well as cell proliferation. On the other hand, the cell cycle process in the presence of EdU can be followed by using cell cytometry. There are four distinct phases in cell proliferation, namely as G1 phase (Gap 1), S-phase (DNA synthesis), G2 phase (Gap 2) and M phase (mitosis). Non-proliferative cells are in the G1 phase. When the cells undergo DNA replication and division, the cells enter the G2/M phases. The S-phase is located between the G1 and G2 phases. As shown in Fig. S6 (ESI $\dagger$ ), two significant peaks of the G1 phase and the G2/M phase are detected. The short period between G1 and G2 is the S-phase.

To understand the relationship between the fluorescence intensity and EdU/dye (1:1, M/M) concentration, we have treated HeLa cells with different EdU/dye concentrations varying from $10 \mu \mathrm{M}$ to $200 \mu \mathrm{M}$ for the same labelling duration. From the results shown in Fig. 3, the fluorescence from the HeLa cells becomes stronger upon increasing the EdU/dye concentration from 10 to $100 \mu \mathrm{M}$ (Fig. S8 and S9, ESI $\dagger$ ). The same phenomenon was observed when the AIEgens were replaced by Alexa647-azide, a commercial dye, but at a much narrow concentration range (10 to $40 \mu \mathrm{M}$ ). A further increase of the EdU/dye concentration will lead to a dramatic drop in PL intensity. It is attributed to the ACQ effect of Alexa647-azide. In contrast, TPE-Py- $\mathrm{N}_{3}$ and $\mathrm{Cy}-\mathrm{Py}-\mathrm{N}_{3}$ exhibit AIE features. They form aggregates at high concentration, which emit much brighter than their single molecular form. Although a small emission drop occurs at high EdU/dye concentration $(200 \mu \mathrm{M})$, possibly due to the complexity of the cellular environment, the much broader working concentration range and brighter emission of AIEgens than those of Alexa647-azide make them more promising candidates for DNA synthesis detection.

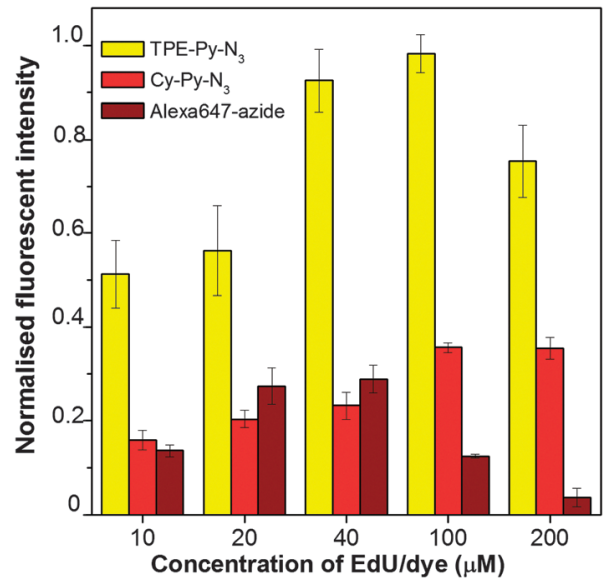

Fig. 3 Normalized fluorescence intensity of HeLa cells incubated at different concentrations of EdU/dye (1:1, M/M).

Toxicity may be induced when EdU is used at high concentration. To determine whether the EdU incorporation will affect the cell viability and the kinetics for DNA replication, the cytotoxicity of EdU was evaluated using MTT assay. No significant change in the cell viability when up to $200 \mu \mathrm{M}$ EdU was added to the culture medium (Fig. S10, ESI $\dagger$ ). This result further confirms that the PL drop in Alexa647-azide is solely because of its ACQ effect rather than associated with the EdU incorporation.

Photostability is one of the key criteria for the practical use of fluorescent probes. Alexa Fluor dyes are known as "premium" fluorophores due to their excellent brightness and good photostability. ${ }^{26,27}$ To compare the photo-bleaching resistance between AIEgens and Alexa647-azide, continuous scanning of their stained HeLa cells by UV irradiation was carried out and the PL intensity at each scan was recorded. Three sets of HeLa cells were first incubated in a medium with $20 \mu \mathrm{M}$ EdU for $24 \mathrm{~h}$. The cells were then stained with TPE-Py- $\mathrm{N}_{3}, \mathrm{Cy}-\mathrm{Py}-\mathrm{N}_{3}$, and

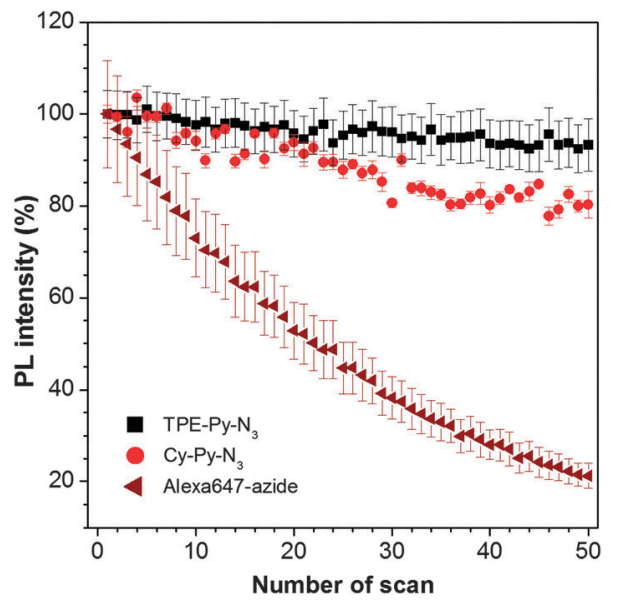

Fig. 4 Change in PL of dye-labelled HeLa cells with increasing irradiation time. Excitation wavelength: $442 \mathrm{~nm}\left(\mathrm{TPE}-\mathrm{Py}-\mathrm{N}_{3}\right), 458 \mathrm{~nm}\left(\mathrm{Cy}-\mathrm{Py}-\mathrm{N}_{3}\right)$ and $633 \mathrm{~nm}$ (Alexa647-azide); emission filter: 450-750 nm (TPE-Py- $\mathrm{N}_{3}$ ), 480-750 nm (Cy-Py- $\mathrm{N}_{3}$ ) and 640-750 nm (Alexa647-azide). Irradiation time: 5.24 s per scan. Laser power: $0.3 \mu \mathrm{W}$. 
Alexa647-azide dye at $20 \mu \mathrm{M}$ for $30 \mathrm{~min}$, respectively. The excitation power from $442 \mathrm{~nm}, 458 \mathrm{~nm}$ and $633 \mathrm{~nm}$ channels of the microscope was unified as $0.3 \mu \mathrm{W}$. The initial fluorescence intensity for the dyes was normalized and the percentage of intensity loss was calculated. As shown in Fig. 3, no significant PL loss was observed in TPE-Py- $\mathrm{N}_{3}$ and $\mathrm{Cy}-\mathrm{Py}-\mathrm{N}_{3}$ after 50 scans in a total irradiation time of $5 \mathrm{~min}$, while more than $80 \%$ signal loss was recorded for Alexa647-azide. The nuclei of HeLa cells stained with AIEgens can still be observed clearly, as revealed by the fluorescent images shown in Fig. S11 (ESI $\dagger$ ). These results suggest that the AIEgens presented here show much higher photo-bleaching resistance than Alexa647-azide (Fig. 4).

\section{Conclusion}

In this work, TPE-Py- $\mathrm{N}_{3}$ and $\mathrm{Cy}-\mathrm{Py}-\mathrm{N}_{3}$ with AIE features were synthesized and utilized as fluorescent agents for detecting S-phase DNA synthesis and cell proliferation. Thanks to their high brightness, superior photostability and high tolerance to concentration change, they are promising alternatives for the commercial Alexa-azide dyes. Coupled with their synthetic accessibility and low cost, they can be promising materials for many high-throughput studies.

\section{Acknowledgements}

This work was partially supported by the National Basic Research Program of China (973 Program; 2013CB834701), the University Grants Committee of Hong Kong (AoE/P-03/08), the Research Grants Council of Hong Kong (604913/6301614 and N_HKUST604/14), and the Innovation and Technology Commission (ITCPD/17-9). B. Z. T. is grateful for the support from the Guangdong Innovative Research Team Program of China (201101C0105067115).

\section{Notes and references}

1 J. E. J. Ferrell, T. Y. Tsai and Q. Yang, Cell, 2011, 144, 874-885.

2 J. M. Enserink, M. B. Smolka, H. Zhou and R. D. Kolodner, J. Cell Biol., 2006, 175, 729-741.

3 H. M. Meng, T. Fu, X. B. Zhang, N. N. Wang, W. H. Tan, G. L. Shen and R. Q. Yu, Anal. Chem., 2012, 84, 2124-2128.

4 H. R. Maurer, Cell Proliferation, 1981, 14, 111-120.

5 H. Gratzner, Science, 1982, 218, 474-475.
6 A. C. Begg, N. J. McNally, D. C. Shrieve and H. Karcher, Cytometry, 1985, 6, 620-626.

7 W. Beisker, F. Dolbeare and J. W. Gray, Cytometry, 1987, 8, 235-239.

8 F. Dolbeare, H. Gratzner, M. Pallavicini and J. W. Gray, Proc. Natl. Acad. Sci. U. S. A., 1983, 80, 5573-5577.

9 S. Buck, J. Bradford, K. R. Gee, B. J. Agnew, S. T. Clarke and A. Salic, BioTechniques, 2008, 44, 927-929.

10 A. Salic and T. J. Mitchison, Proc. Natl. Acad. Sci. U. S. A., 2008, 105, 2415-2420.

11 S. Diermeier-Dauche, S. T. Clarke, D. Hill, A. VollmannZwerenz, J. A. Bradford and G. Brockhoff, Cytometry, Part A, 2009, 75, 535-546.

12 C. W. Tang and S. A. Vanslyke, Appl. Phys. Lett., 1987, 51, 913-915.

13 H. Saigusa and E. C. Lim, Acc. Chem. Res., 1996, 29, 171-178. 14 L. Chen, S. Xu, D. Mcbranch and D. Whitten, J. Am. Chem. Soc., 2000, 122, 9302-9303.

15 J. Luo, Z. Xie, J. W. Y. Lam, Y. Dong, S. M. F. Lo, I. D. Williams, D. Zhu and B. Z. Tang, Chem. Commun., 2001, 1740-1741.

16 Y. Hong, J. W. Y. Lam and B. Z. Tang, Chem. Commun., 2009, 4332-4353.

17 Y. Hong, J. W. Y. Lam and B. Z. Tang, Chem. Soc. Rev., 2011, 40, 5361-5388.

18 J. Mei, Y. Hong, J. W. Y. Lam, A. Qin, Y. Tang and B. Z. Tang, Adv. Mater., 2014, 26, 5429-5479.

19 R. T. K. Kwok, C. W. T. Leung, J. W. Y. Lam and B. Z. Tang, Chem. Soc. Rev., 2015, DOI: 10.1039/c4cs00325j.

20 D. Ding, K. Li, B. Liu and B. Z. Tang, Acc. Chem. Res., 2013, 46, 2441-2453.

21 D. Ding, J. Liu, G. Feng, K. Li, Y. Hu and B. Liu, Small, 2013, 9, 3093-3102.

22 W. Qin, D. Ding, J. Liu, W. Yuan, Y. Hu, B. Liu and B. Z. Tang, Adv. Funct. Mater., 2012, 22, 771-779.

23 J. Geng, K. Li, W. Qin, B. Z. Tang and B. Liu, Part. Part. Syst. Charact., 2014, 31, 1238-1243.

24 H. Shi, N. Zhao, D. Ding, J. Liang, B. Z. Tang and B. Liu, Org. Biomol. Chem., 2013, 11, 7289-7296.

25 R. Hu, E. Lager, A. Aguilar-Aguilar, J. Liu, J. W. Y. Lam, H. H. Y. Sung, I. D. Williams, Y. Zhong, K. Wong and B. Z. Tang, J. Phys. Chem., 2009, 113, 15845-15853.

26 G. P. Anderson and N. L. Nerurkar, J. Immunol. Methods, 2002, 271, 17-24.

27 H. Martin, C. Murray, J. Christeller and T. McGhie, Anal. Biochem., 2008, 381, 107-112. 